\title{
A survey of steroid-related osteoporosis diagnosis, prevention and treatment practices of pediatric rheumatologists in North America
}

Arzu Soybilgic ${ }^{*}$, Melissa Tesher, Linda Wagner-Weiner and Karen B Onel

\begin{abstract}
Background: The purpose of our study is to assess practices of North American pediatric rheumatologists regarding monitoring, prevention, and treatment of low bone mineral density (BMD) in children on long-term glucocorticoid treatment.

Long-term glucocorticoid therapy is associated with accelerated bone loss. Children with JIA and lupus have low baseline BMD and incident vertebral fractures commonly occur in these groups of patients even after a relatively short period of time being on systemic glucocorticoids. There are no established guidelines for identification, prevention, and treatment of glucocorticoid-induced bone loss in children.
\end{abstract}

Methods: A cross-sectional online survey was conducted with 199 physicians who were listed in the ACR database as practicing pediatric rheumatology in North America.

Results: 86 physicians (43\%) responded; 87\% were board-certified in pediatric rheumatology. 95\% used dual energy X-ray absorptiometry as their primary modality for assessing BMD. 79\% "rarely" or "never" obtained a baseline BMD measurement prior to initiation of glucocorticoid therapy. 42\% of respondents followed BMD annually. 93\% "frequently" or "always" prescribed calcium for patients on long-term corticosteroid therapy; $81 \%$ "frequently" or "always" prescribed vitamin D. In patients diagnosed with osteoporosis, 35\%-50 \% of the practitioners "sometimes", "frequently" or "always" prescribed bisphosphonates. Bisphosphonates are prescribed at similar rates for male and female patients, and slightly more frequently for pubertal than for pre-pubertal patients. 96\% of respondents "rarely" or "never" prescribed calcitonin for patients on long-term glucocorticoid therapy; $92 \%$ "rarely" or "never" prescribe this medication for patients with known osteopenia or osteoporosis.

Conclusions: Utilization of DXA in children on long-term corticosteroid therapy varies greatly among North American pediatric rheumatologists. Most respondents do not screen for low BMD on a regular basis despite acknowledging the risks of bone loss in this population. Broad consensus appears to be present among practitioners favoring the prescription of calcium and vitamin D for patients receiving long-term corticosteroid therapy. Relatively few respondents consistently recommend bisphosphonate therapy, even for patients with known low bone density; calcitonin is rarely used. These data underscore the need for studies to acquire specific data on bone loss, and its prevention and treatment in young patients on long-term glucocorticoid therapy.

Keywords: Pediatric, Rheumatology, Systemic, Juvenile, Idiopathic, Arthritis, Osteoporosis, Corticosteroids, North America

* Correspondence: arzu.soybilgic@gmail.com

University of Illinois at Chicago, Chicago, IL, USA 


\section{Background}

Long-term glucocorticoid therapy is known to be associated with accelerated bone loss, causing increased risk of osteoporosis and fracture [1]. Low bone density is common in juvenile idiopathic arthritis (JIA), lupus and other pediatric rheumatologic diseases [2-7]. Many patients with JIA have low BMD, even at baseline before the start of systemic glucocorticoid treatment. $30 \%$ of mildly to moderately ill pre-pubertal JIA patients who had never been treated with corticosteroids had low total body BMD [8]. Asymptomatic vertebral fractures are an under-recognized problem in children with inflammatory disorders and can be present prior to prolonged glucocorticoid exposure in pediatric rheumatology patients $[9,10]$.

The ACR has published clinical guidelines for diagnosis and management of osteoporosis for adults on long-term glucocorticoid therapy [11]. Despite guidelines, some studies show that many patients treated with glucocorticoids do not receive any treatment to prevent bone loss $[12,13]$. A recent survey of adult rheumatologists revealed significant variability in corticosteroid - induced osteoporosis management [14]. There is even less experience on this medical issue in pediatrics, as there are no established clinical guidelines for identification and prevention of glucocorticoid-induced bone loss in children. Furthermore, once the diagnosis of osteopenia/osteoporosis is established in children, treatment options are limited and poorly studied.

There are several studies reporting that bisphosphonates are safe and effective in children [15-21]. However, there are still concerns among pediatric rheumatologists about the long-term effects of bisphosphonate use in children. Pediatric rheumatologists hesitate to prescribe bisphosphonates to children because the possible longterm adverse effects, the necessary length of treatment and the maximal bone mass gain that can be achieved in children are all unknown.

With this survey, we aimed to assess current practices of North American pediatric rheumatologists regarding monitoring, prevention, and treatment of osteoporosis and osteopenia in children on long-term glucocorticoid treatment.

\section{Methods}

\section{Sample population}

Using electronic mail, an online, self-administered survey was sent to 199 physicians practicing pediatric rheumatology in North America. Physicians were surveyed using a questionnaire probing the diagnosis, prevention, treatment, and monitoring of osteoporosis in children receiving long-term oral systemic corticosteroid therapy.

Ethics approval was granted by the University of Chicago Institutional Review Board.

\section{Survey design}

The survey was comprised of 17 items (see Additional file 1). It addressed three major themes in management of glucocorticoid-induced osteoporosis in children: 1) Preferred methods of diagnosis 2) Current approaches to prevention 3) Preferred treatment choices.

\section{Analysis}

Data analysis included descriptive statistics applied to the closed-ended questions, expressed as frequency (percentages) for categorical variables.

\section{Results}

86 of the 199 physicians who were sent the survey completed the survey ( $43 \%$ response rate), of which $85 \%$ were board certified to practice pediatric rheumatology in the US. $84 \%$ of the respondents were pediatric rheumatologists, $10 \%$ were medicine/pediatric rheumatologists, $1 \%$ pediatric rheumatology fellow, $1 \%$ adult rheumatologist, and $4 \%$ listed themselves as "other". The most common practice setting, with $86 \%$, was an "Academic Medical Center". $5 \%$ of the respondents practiced at a community hospital, $5 \%$ in private practice, and $4 \%$ reported their practice setting as "other".

$46 \%$ of the physicians reported that they would consider measures to identify or prevent corticosteroid-induced bone loss in patients treated with any steroid dose. 31\% would consider such measures only at prednisone doses greater than $0.5 \mathrm{mg} / \mathrm{kg} / \mathrm{day}, 17 \%$ at doses greater than 1 $\mathrm{mg} / \mathrm{kg} /$ day, $5 \%$ at doses greater than $2 \mathrm{mg} / \mathrm{kg} /$ day.

$80 \%$ of the physicians never or rarely obtained a baseline BMD measurement, by any method, before initiating long-term ( $>6$ months) glucocorticoid treatment; $11 \%$ did so sometimes, $7 \%$ frequently. Only $2 \%$ of the physicians always obtained a baseline measurement before initiating long-term glucocorticoid treatment.

The most commonly used tool for initial BMD measurement and to monitor steroid-related bone loss was DXA (96\%); $4 \%$ of the physicians used quantitative CT, and none of the responders used quantitative ultrasound of bone or single X-ray absorptiometry of bone for these purposes. $5 \%$ of the physicians obtained follow-up BMD measurements every 6 months, $42 \%$ annually, $5 \%$ every 18 months, and $16 \%$ less frequently than every two years. $2 \%$ never obtained follow-up BMD measurements. Only $6 \%$ of physicians reported having a written policy in their department regarding the frequency of BMD measurements in children on long-term glucocorticoid treatment.

93\% of the physicians reported starting calcium supplements frequently or always for patients who are on longterm corticosteroid treatment. Vitamin D supplements were given frequently or always by $80 \%$ of physicians. 
$40 \%$ of the responders prescribed combined calcium/ vitamin tablets.

In patients diagnosed with either osteopenia or osteoporosis, between $35 \%$ and $50 \%$ of the practitioners "sometimes", "frequently" or "always" prescribed bisphosphonates. Bisphosphonates are prescribed at similar rates for male and female patients, and slightly more frequently for pubertal than for pre-pubertal patients. 96\% of respondents "rarely" or "never" prescribe calcitonin for patients on long-term glucocorticoid therapy, and 92\% "rarely" or "never" prescribe this medication for patients with known osteopenia or osteoporosis.

\section{Discussion}

Low bone density is common in children with JIA, lupus and other rheumatologic diseases [2-5]. 30\% of mildly to moderately ill pre-pubertal JIA patients who had never been treated with corticosteroids had low total body BMD [8]. Patients with juvenile SLE have a low bone mass without catch-up growth over time, causing a reduction of peak bone mass with high risk of osteoporosis in early adulthood [7]. Local inflammatory factors, decreased physical activity, nutritional imbalances, and medications have all been implicated in bone loss [22,23]. In our study, many physicians (46\%) reported that they would consider measures to identify or prevent corticosteroid-induced bone loss at any steroid dose. However, the preponderance $(80 \%)$ of the physicians never or rarely obtained a baseline BMD measurement, by any method, before initiating long-term ( $>6$ months) glucocorticoid treatment.

Vertebral fractures are an under-recognized problem in children with inflammatory disorders and they can be present prior to prolonged glucocorticoid exposure. A recent study reported that the incidence of vertebral fractures in children with rheumatologic diseases in the 12 months following glucocorticoid initiation was $6 \%$, and most children were asymptomatic [10]. Another study on children with rheumatic conditions reported that $7 \%$ of children had vertebral fractures within 30 days of initiating glucocorticoids [9]. Studies in adults have shown that patients with glucocorticoid-induced osteoporosis experience fragility fractures at better DXA scores than those with postmenopausal or age-related osteoporosis. This might be explained, at least in part, by the effects of glucocorticoids not only on osteoclasts but also on osteoblasts and osteocytes [24]. Therefore, prevention and early diagnosis of low bone density is important in pediatric rheumatology patients to prevent fragility fractures.

Per the guidelines published by The International Society for Clinical Densitometry in 2013, in the absence of vertebral compression (crush) fractures, the diagnosis of osteoporosis in children is indicated by the presence of both a clinically significant fracture history and
BMD Z-score $\leq-2.0$. The Society stresses that diagnosis of osteoporosis in children and adolescents should not be made on the basis of densitometric criteria alone. However, they recommend that in patients with primary bone disease, or at risk for a secondary bone disease, a DXA should be performed when the patient may benefit from interventions to decrease their elevated risk of a clinically significant fracture, and the DXA results will influence that management. Per these guidelines, DXA is the preferred method for assessing BMC and areal BMD in children. Despite the data showing the high frequency of asymptomatic fragility fractures in children with rheumatologic diseases who are on long-term glucocorticoids and recommendations by The International Society for Clinical Densitometry summarized above, we found in our study that only $42 \%$ of the physicians obtained follow-up BMD measurements annually to screen for low bone density in patients who are on long-term glucocorticoid treatment. Few physicians (only $6 \%$ ) had a written policy in their department regarding the frequency of BMD measurements in children on long-term glucocorticoid treatment.

In our study, DXA was the most commonly utilized diagnostic tool for diagnosis and follow-up of glucocorticoid-induced osteoporosis. None of the physicians who responded to our survey reported using bone ultrasound to monitor bone health in pediatric rheumatology patients who were on long-term glucocorticoid treatment. However, there is a growing body of evidence regarding the use of bone ultrasound in children to monitor bone density. Quantitative ultrasound (QUS) can be used for radiationfree assessment of bone density and "bone quality" by measurement of the ultrasound wave attenuation by bone (BUA) in children with JIA. Bone speed of sound (SOS) shows a significant correlation with BMD as measured by DXA. Portability, ease of use, lower cost, and absence of radiation make QUS of bone a promising means of evaluating BMD in children [25-31].

As stated earlier, there are no guidelines for prevention or treatment of glucocorticoid-induced osteoporosis in children. In our study, $93 \%$ of the physicians reported starting calcium supplements frequently or always as a preventative measure for patients who are on long- term corticosteroid treatment. Vitamin D supplements were given always or frequently by $80 \%$ of the respondents. In our study, $62 \%$ and $49 \%$ of the physicians never or rarely prescribed bisphosphonates for their pre-pubertal and pubertal female patients, respectively, with documented osteoporosis; $60 \%$ and $50 \%$ of the physicians never or rarely prescribed bisphosphonates for their pre-pubertal and pubertal male patients. A possible reason for its limited use in pediatrics is the concern of long-term side effects related to the persistence of bisphosphonates in bone. However, only bone tissue appears to be affected 
by bisphosphonates in vivo: the very rapid uptake by bone ensures that the other tissues are exposed for only a short period to these drugs (the half-life of circulating bisphosphonates in humans is $0.5-2$ hours), and as far as we know, there is no evidence that bisphosphonates maintain any pharmacologic activity once sequestered in the bone [32]. In a prospective multicenter study, oral alendronate was found to be safe and efficacious for the treatment of osteoporosis in diffuse connective tissue diseases in children [15]. Several other studies to date have shown safety and efficacy of bisphosphonates in children $[15,21,33,34]$. Most commonly reported adverse effects included acute phase type of reactions and flulike reactions (fever, muscle aches, bone pain) with IV infusion of bisphosphonates which usually responds to acetaminophen or ibuprofen and did not usually occur with further infusions [35-38]. Self-limited mild abdominal pain, nausea, and vomiting after the first infusion of bisphosphonates have also been reported [35]. Transient decreases in serum calcium and phosphate levels after treatment with intravenous pamidronate have been reported [16,17,39-41].

Several studies reported normal growth during treatment with bisphosphonates [15,36,37,42]. Metaphyseal banding (zebra lines) can be seen on the radiographs of children receiving cyclical bisphosphonate therapy [43]. The linear growth was found to be normal in several studies after use of bisphosphonates in children [17,44-46]. There were no effects of commonly used bisphosphonates on the growth plate and bone ages of children corresponded with their chronological age [17]. Bisphosphonate-associated osteonecrosis of the jaw has been reported in adults, but no cases have been reported in children so far [47].

There is a hesitance to use bisphosphonates in girls and young women of childbearing age due to concerns for potential unfavorable effects of bisphosphonate treatment on the fetus, mainly in the skeleton. Since bisphosphonates are retained for a long time in the human skeleton, concerns have been raised that even pre-pregnancy administration of bisphosphonates may result in embryofetal exposure and alter fetal bone modeling.

A recent study reviewed fifty-one cases of exposure to bisphosphonates before or during pregnancy; none of the pregnancies resulted in skeletal abnormalities or other congenital malformations in the infants [48].

Considering the high incidence of vertebral fractures in children on chronic glucocorticoid treatment and the data supporting safety and efficacy of bisphosphonates in children in general, it can be argued that the benefits of bisphosphonate therapy may outweigh the potential risks in patients with low bone density and frequent fragility fractures. Therefore, bisphosphonates should be considered as a treatment option for children who are on long-term glucocorticoid treatment and have documented osteopenia/osteoporosis.

Calcitonin is a naturally occurring peptide, which inhibits bone resorption by osteoclasts, and is useful for treatment of osteoporosis, reducing vertebral and hip fractures in adult patients. It is usually well tolerated, and its main side-effects are gastrointestinal. It can be administered by injection, orally or intranasally. Calcitonin has been shown to be safe and effective in treatment of steroid-induced osteoporosis in children with nephrotic syndrome [49]. Another recent study of intranasal calcitonin in 10 children with JIA showed a decrease in bone resorption markers and an increase in BMD [50]. Also, calcitonin can rapidly improve symptoms of vertebral fractures [51]. However, because the evidence is limited on the use of calcitonin in children, pediatric rheumatologists infrequently utilize it. 96\% of respondents reported "rarely" or "never" prescribing calcitonin for patients on long-term glucocorticoid therapy, and 92\% "rarely" or "never" prescribe this medication even for patients with known osteopenia or osteoporosis. More studies are needed in this area.

\section{Conclusions}

Broad consensus appears to be present among North American pediatric rheumatologists favoring the prescription of calcium and vitamin $\mathrm{D}$ for pediatric patients on long-term corticosteroid therapy.

Despite the data showing the high incidence of osteoporosis and incident vertebral fractures in children on long-term glucocorticoids, relatively few respondents consistently recommend bisphosphonate therapy, even for patients with known osteopenia or osteoporosis, and calcitonin is rarely used. Furthermore, there is high variability of utilization of DXA in children on long-term corticosteroid treatment. These data underscore the need for more research on bone loss, and its prevention and treatment in young patients on long-term glucocorticoid therapy.

\section{Additional file}

Additional file 1: Survey questions.

Abbreviations

BMD: Bone mineral density; BMC: Bone mineral content; DXA: Dual-energy X-ray absorptiometry; SLE: Systemic lupus erythematosus; JIA: Juvenile idiopathic arthritis; Bone US: Bone ultrasound; SOS: Speed of sound.

Competing interests

The authors declare that they have no competing interests.

\section{Authors' contributions}

AS conceived the study, AS, MT, LWW, KBO participated in its design, AS have collected the data and drafted the manuscript, MT, LWW, KBO have been involved in revising it critically for important intellectual content; all of the authors have given final approval of the version to be published and agree to be accountable for all aspects of the work in ensuring that questions related to 
the accuracy and integrity of any part of the work are appropriately investigated and resolved. All authors read and approved the final manuscript.

Received: 25 February 2014 Accepted: 25 June 2014 Published: 9 July 2014

\section{References}

1. Van Staa TP, Leufkens HG, Abenhaim L, Zhang B, Cooper C: Oral corticosteroids and fracture risk: relationship to daily and cumulative doses. Rheumatology 2000, 39(12):1383-1389. PubMed PMID: 11136882.

2. Brabnikova MK: Secondary osteoporosis in patients with juvenile idiopathic arthritis. J Osteoporos 2011, 2011:569417. PubMed PMID: 21403891. Pubmed Central PMCID: 3043287.

3. MCDonagh JE: Osteoporosis in juvenile idiopathic arthritis. Curr Opin Rheumatol 2001, 13(5):399-404. PubMed PMID: 11604595.

4. Uziel Y, Zifman E, Hashkes PJ: Osteoporosis in children: pediatric and pediatric rheumatology perspective: a review. Pediatr Rheumatol Online J 2009, 7:16. PubMed PMID: 19835571. Pubmed Central PMCID: 2768686

5. Roth J, Bechtold S, Borte G, Dressler F, Girschick H, Borte M: Diagnosis, prophylaxis and therapy of osteoporosis in juvenile idiopathic arthritis: consensus statement of the German Association for Pediatric Rheumatology. Z Rheumatol 2007, 66(5):434-440. PubMed PMID: 17522871. Diagnose, Prophylaxe und Therapie der Osteoporose bei juveniler idiopathischer Arthritis: Konsensusstatement der Gesellschaft fur Kinder- und Jugendrheumatologie.

6. Roth J, Bechtold S, Borte G, Dressler F, Girschick HJ, Borte M: Osteoporosis in juvenile idiopathic arthritis-a practical approach to diagnosis and therapy. Eur J Pediatr 2007, 166(8):775-784. PubMed PMID: 17436015.

7. Stagi S, Cavalli L, Bertini F, Cerinic MM, Brandi ML, Falcini F: Cross-sectional and longitudinal evaluation of bone mass and quality in children and young adults with juvenile onset systemic lupus erythematosus (JSLE): role of bone mass determinants analyzed by DXA, PQCT and QUS. Lupus 2014, 23(1):57-68. PubMed PMID: 24218395.

8. Henderson CJ, Cawkwell GD, Specker BL, Sierra RI, Wilmott RW, Campaigne BN, Lowell DL: Predictors of total body bone mineral density in noncorticosteroid-treated prepubertal children with juvenile rheumatoid arthritis. Arthritis Rheum 1997, 40(11):1967-1975. PubMed PMID: 9365085.

9. Huber AM, Gaboury I, Cabral DA, Lang B, Ni A, Stephure D, Taback S, Dent P, Ellsworth J, LeBlanc C, Saint-Cyr C, Scuccimarri R, Hay J, Lentle B, Matzinger M, Shenouda N, Moher D, Rauch F, Siminoski K, Ward LM, Canadian SteroidAssociated Osteoporosis in the Pediatric Population (STOPP) Consortium: Prevalent vertebral fractures among children initiating glucocorticoid therapy for the treatment of rheumatic disorders. Arthritis Care Res 2010, 62(4):516-526. PubMed PMID: 20391507.

10. Rodd C, Lang B, Ramsay T, Alos N, Huber AM, Cabral DA, Scuccimarri R, Miettunen PM, Roth J, Atkinson SA, Couch R, Cummings EA, Dent PB, Ellsworth J, Hay J, Houghton K, Jurencak R, Larché M, LeBlanc C, Oen K, Saint-Cyr C, Stein R, Stephure D, Taback S, Lentle B, Matzinger M, Shenouda N, Moher D, Rauch F, Siminoski K, et al: Incident vertebral fractures among children with rheumatic disorders 12 months after glucocorticoid initiation: a national observational study. Arthritis Care Res 2012, 64(1):122-131. PubMed PMID: 22213727.

11. Grossman JM, Gordon R, Ranganath VK, Deal C, Caplan L, Chen W, Curtis JR, Furst DE, McMahon M, Patkar NM, Volkmann E, Saag KG: American College of Rheumatology 2010 recommendations for the prevention and treatment of glucocorticoid-induced osteoporosis. Arthritis Care Res 2010, 62(11):1515-1526. PubMed PMID: 20662044

12. Peat ID, Healy S, Reid DM, Ralston SH: Steroid induced osteoporosis: an opportunity for prevention? Ann Rheum Dis 1995, 54(1):66-68. PubMed PMID: 7880126. Pubmed Central PMCID: 1005515.

13. Walsh L, Wong CA, Pringle M, Tattersfield AE: Use of oral corticosteroids in the community and the prevention of secondary osteoporosis: a cross sectional study. BMJ 1996, 313(7053):344-346. PubMed PMID: 8760745. Pubmed Central PMCID: 2351752

14. Soucy E, Bellamy N, Adachi JD, Pope JE, Flynn J, Sutton E, Campbell J: A Canadian survey on the management of corticosteroid induced osteoporosis by rheumatologists. J Rheumatol 2000, 27(6):1506-1512. PubMed PMID: 10852279

15. Bianchi ML, Cimaz R, Bardare M, Zulian F, Lepore L, Boncompagni A, Corona F, Luisetto G, Giuntini D, Picco P, Brandi ML, Falcini F: Efficacy and safety of alendronate for the treatment of osteoporosis in diffuse connective tissue diseases in children: a prospective multicenter study. Arthritis Rheum 2000, 43(9):1960-1966. PubMed PMID: 11014345.

16. DiMeglio LA, Ford L, McClintock C, Peacock M: Intravenous pamidronate treatment of children under 36 months of age with osteogenesis imperfecta. Bone 2004, 35(5):1038-1045. PubMed PMID: 15542028.

17. Glorieux FH, Bishop NJ, Plotkin H, Chabot G, Lanoue G, Travers R: Cyclic administration of pamidronate in children with severe osteogenesis imperfecta. N Engl J Med 1998, 339(14):947-952. PubMed PMID: 9753709.

18. Lee JM, Kim JE, Bae SH, Hah JO: Efficacy of pamidronate in children with low bone mineral density during and after chemotherapy for acute lymphoblastic leukemia and non-Hodgkin lymphoma. Blood Res 2013, 48(2):99-106. PubMed PMID: 23826578. Pubmed Central PMCID: 3698414.

19. Salehpour S, Tavakkoli S: Cyclic pamidronate therapy in children with osteogenesis imperfecta. J Pediatr Endocrinol Metab 2010, 23(1-2):73-80. PubMed PMID: 20432809.

20. Stuart M: Efficacy and safety of alendronate for the treatment of osteoporosis in diffuse connective tissue diseases in children. Clin Pediatr 2002, 41(5):362-363. PubMed PMID: 12086205.

21. Unal E, Abaci A, Bober E, Buyukgebiz A: Efficacy and safety of oral alendronate treatment in children and adolescents with osteoporosis. J Pediatr Endocrinol Metab 2006, 19(4):523-528. PubMed PMID: 16759038.

22. Gough A, Sambrook P, Devlin J, Huissoon A, Njeh C, Robbins S, Nguyen T, Emery P: Osteoclastic activation is the principal mechanism leading to secondary osteoporosis in rheumatoid arthritis. J Rheumatol 1998, 25(7):1282-1289. PubMed PMID: 9676757.

23. Deodhar AA, Woolf AD: Bone mass measurement and bone metabolism in rheumatoid arthritis: a review. Br J Rheumatol 1996, 35(4):309-322. PubMed PMID: 8624634.

24. Buehring B, Viswanathan R, Binkley N, Busse W: Glucocorticoid-induced osteoporosis: an update on effects and management. J Allergy Clin Immunol 2013, 132(5):1019-1030. PubMed PMID: 24176682.

25. Cimaz R: Osteoporosis in childhood rheumatic diseases: prevention and therapy. Best Pract Res Clin Rheumatol 2002, 16(3):397-409. PubMed PMID: 12387807.

26. Falcini F, Bindi G, Ermini M, Galluzzi F, Poggi G, Rossi S, Masi L, Cimaz R, Brandi ML: Comparison of quantitative calcaneal ultrasound and dual energy X-ray absorptiometry in the evaluation of osteoporotic risk in children with chronic rheumatic diseases. Calcif Tissue Int 2000, 67(1):19-23. PubMed PMID: 10908407.

27. Falcini F, Bindi G, Simonini G, Stagi S, Galluzzi F, Masi L, Cimaz R: Bone status evaluation with calcaneal ultrasound in children with chronic rheumatic diseases. A one year followup study. J Rheumatol 2003, 30(1):179-184. PubMed PMID: 12508409.

28. Lernbass I, Wutzl A, Grisar J, Schett G, Redlich K, Spitzauer S, Grampp S, Imhof H, Peterlik M, Pietschmann P: Quantitative ultrasound in the assessment of bone status of patients suffering from rheumatic diseases. Skeletal Radiol 2002, 31(5):270-276. PubMed PMID: 11981603.

29. Baroncelli Gl, Federico G, Bertelloni S, Sodini F, De Terlizzi F, Cadossi R, Saggese G: Assessment of bone quality by quantitative ultrasound of proximal phalanges of the hand and fracture rate in children and adolescents with bone and mineral disorders. Pediatr Res 2003, 54(1):125-136. PubMed PMID: 12700367.

30. Baroncelli Gl, Federico G, Bertelloni S, De Terlizzi F, Cadossi R, Saggese G: Bone quality assessment by quantitative ultrasound of proximal phalanxes of the hand in healthy subjects aged 3-21 years. Pediatr Res 2001, 49(5):713-718. PubMed PMID: 11328957.

31. Njeh CF, Shaw N, Gardner-Medwin JM, Boivin CM, Southwood TR: Use of quantitative ultrasound to assess bone status in children with juvenile idiopathic arthritis: a pilot study. J Clin Densitom 2000, 3(3):251-260. PubMed PMID: 11090232.

32. Fleisch H: Bisphosphonates-history and experimental basis. Bone 1987 8(Suppl 1):S23-S28. PubMed PMID: 3318890

33. Acott PD, Wong JA, Lang BA, Crocker JF: Pamidronate treatment of pediatric fracture patients on chronic steroid therapy. Pediatr Nephrol 2005, 20(3):368-373. PubMed PMID: 15690187.

34. Falcini F, Trapani S, Civinini R, Capone A, Ermini M, Bartolozzi G: The primary role of steroids on the osteoporosis in juvenile rheumatoid patients evaluated by dual energy X-ray absorptiometry. J Endocrinol Invest 1996, 19(3):165-169. PubMed PMID: 8743282.

35. Noguera A, Ros JB, Pavia C, Alcover E, Valls C, Villaronga M, González E: Bisphosphonates, a new treatment for glucocorticoid-induced 
osteoporosis in children. J Pediatr Endocrinol Metab 2003, 16(4):529-536. PubMed PMID: 12793604.

36. Gandrud LM, Cheung JC, Daniels MW, Bachrach LK: Low-dose intravenous pamidronate reduces fractures in childhood osteoporosis. J Pediatr Endocrinol Metab 2003, 16(6):887-892. PubMed PMID: 12948302.

37. Brumsen C, Hamdy NA, Papapoulos SE: Long-term effects of bisphosphonates on the growing skeleton. Studies of young patients with severe osteoporosis. Medicine 1997, 76(4):266-283. PubMed PMID: 9279333.

38. Shaw NJ, Boivin CM, Crabtree NJ: Intravenous pamidronate in juvenile osteoporosis. Arch Dis Child 2000, 83(2):143-145. PubMed PMID: 10906023. Pubmed Central PMCID: 1718443

39. Rauch F, Plotkin H, Travers R, Zeitlin L, Glorieux FH: Osteogenesis imperfecta types I, III, and IV: effect of pamidronate therapy on bone and mineral metabolism. J Clin Endocrinol Metab 2003, 88(3):986-992. PubMed PMID: 12629073

40. Banerjee I, Shortland GJ, Evans WD, Gregory JW: Osteogenesis imperfecta and intravenous pamidronate. Arch Dis Child 2002, 87(6):562-563. PubMed PMID: 12456578. Pubmed Central PMCID: 1755843.

41. Giraud F, Meunier PJ: Effect of cyclical intravenous pamidronate therapy in children with osteogenesis imperfecta. Open-label study in seven patients. Joint Bone Spine 2002, 69(5):486-490.

42. Fernandes JL, Viana SL, Rocha AL, Ribeiro MC, Castro LC: Biphosphonateinduced radiographic changes in two pediatric patients with rheumatic diseases. Skeletal Radiol 2004, 33(12):732-736. PubMed PMID: 15309334.

43. Al Muderis M, Azzopardi T, Cundy P: Zebra lines of pamidronate therapy in children. J Bone Joint Surg Am 2007, 89(7):1511-1516. PubMed PMID: 17606790.

44. Zacharin M, Kanumakala S: Pamidronate treatment of less severe forms of osteogenesis imperfecta in children. J Pediatr Endocrinol Metab 2004, 17(11):1511-1517. PubMed PMID: 15570988.

45. Lee YS, Low SL, Lim LA, Loke KY: Cyclic pamidronate infusion improves bone mineralisation and reduces fracture incidence in osteogenesis imperfecta. Eur J Pediatr 2001, 160(11):641-644. PubMed PMID: 11760017.

46. Bembi B, Parma A, Bottega M, Ceschel S, Zanatta M, Martini C, Ciana G: Intravenous pamidronate treatment in osteogenesis imperfecta. J Pediatr 1997, 131(4):622-625. PubMed PMID: 9386671.

47. Brown JJ, Ramalingam L, Zacharin MR: Bisphosphonate-associated osteonecrosis of the jaw: does it occur in children? Clin Endocrinol (Oxf) 2008, 68(6):863-867. PubMed PMID: 18221397.

48. Djokanovic N, Klieger-Grossmann C, Koren G: Does treatment with bisphosphonates endanger the human pregnancy? J Obstet Gynaecol Can 2008, 30(12):1146-1148. PubMed PMID: 19175968.

49. Nishioka T, Kurayama H, Yasuda T, Udagawa J, Matsumura C, Niimi H: Nasal administration of salmon calcitonin for prevention of glucocorticoidinduced osteoporosis in children with nephrosis. J Pediatr 1991, 118(5):703-707. PubMed PMID: 2019923.

50. Siamopoulou A, Challa A, Kapoglou P, Cholevas V, Mavridis AK, Lapatsanis PD: Effects of intranasal salmon calcitonin in juvenile idiopathic arthritis: an observational study. Calcif Tissue Int 2001, 69(1):25-30. PubMed PMID: 11685430.

51. Knopp-Sihota JA, Newburn-Cook CV, Homik J, Cummings GG, Voaklander D: Calcitonin for treating acute and chronic pain of recent and remote osteoporotic vertebral compression fractures: a systematic review and meta-analysis. Osteoporos Int 2012, 23(1):17-38. PubMed PMID: 21660557.

\section{Submit your next manuscript to BioMed Central and take full advantage of:}

- Convenient online submission

- Thorough peer review

- No space constraints or color figure charges

- Immediate publication on acceptance

- Inclusion in PubMed, CAS, Scopus and Google Scholar

- Research which is freely available for redistribution

Submit your manuscript at www.biomedcentral.com/submit
C Biomed Central 